\title{
Da Angola para a Bahia: permanências do léxico banto
}

\author{
From Angola to Babia: stays of the Bantu lexxicon
}

\author{
Uana Vanessa Pinheiro de Abreu* \\ Universidade Estadual de Feira de Santana \\ Feira de Santana, Bahia, Brasil \\ Norma Lúcia Fernandes de Almeida** \\ Universidade Estadual de Feira de Santana \\ Feira de Santana, Bahia, Brasil \\ Patrício Nunes Barreiros ${ }^{* *}$ \\ Universidade Estadual de Feira de Santana \\ Feira de Santana, Bahia, Brasil
}

\begin{abstract}
Resumo: Neste trabalho apresenta-se uma breve análise bibliográfica da influência que a língua banto tive na formação do Português Brasileiro, tentando mostrar que muitas lexias estão incorporadas na língua nacional de tal forma que os falantes não conseguem perceber nenhuma relação com a língua africana. Para tanto, apresenta-se uma discussão teórica acerca da formação do português brasileiro e, na sequência, analisamos algumas lexias, tomando como base obras lexicográficas.
\end{abstract}

Palavras-chave: Português Brasileiro. Banto. Africa.

\begin{abstract}
This paper presents a brief bibliographical analysis of the influence that the Bantu language had on the formation of Brazilian Portuguese, trying to show that many lexias are incorporated in the national language in such a way that the speakers can not perceive any relation with the African language. For that, a theoretical discussion about the formation of Brazilian Portuguese is presented and, in the sequence, we analyze some lexias, based on lexicographic works.
\end{abstract}

Keywords: Brazilian portuguese. Banto. Africa.

\section{INTRODUÇÃO}

A formação do português brasileiro contou com a participação das línguas indígenas e africanas. Durante as primeiras décadas da colonização a mão de obra escrava era basicamente de origem indígena, mas os índios não conheciam o manejo do engenho e não se adaptaram ao sistema escravocrata instituído na colônia portuguesa. Além disso, muitos índios morreram em decorrência do contato com as novas doenças,

*Mestranda em Estudos Linguísticos pela Universidade Estadual de Feira de Santana, Feira de Santana Bahia - Brasil. E-mail: uanavanessa@hotmail.com,

** Doutora em Linguística, Professora Titular da Universidade Estadual de Feira de Santana, Feira de Santana - Bahia - Brasil. E-mail: norma.uefs@gmail.com.

*** Doutor em Letras e Linguística, professor Titular da Universidade Estadual de Feira de Santana. Email: patricio@uefs.br. 
favorecendo o declínio da escravidão indígena. A vida nos engenhos de açúcar exigiu mão de obra escrava que se adaptasse ao novo potencial econômico do Brasil. Assim, os colonizadores investiram na mão de obra escrava oriunda da África, dando início ao tráfico de africanos escravizados para o Brasil.

Ao chegarem ao seu novo destino, os escravizados eram enviados para as plantações, muitos não tinham contato com o branco, devido às condições de trabalho, com isso ficava mais difícil aprender a nova língua, visto que teriam como modelo outros africanos, os ladinos, que já conheciam um pouco do novo idioma, mas essa aprendizagem ocorria de forma irregular, sem as regras gramaticais, tendo como transferência básica elementos lexicais que propiciassem o entendimento da mensagem, apenas a nível de compreensão básica da comunicação.

Há relatos que enquanto aguardavam (ainda na África) para serem transportados para o Brasil os escravizados acabavam conhecendo algumas palavras do português, uma vez que estavam em contato com pombeiros (os recrutadores) e negreiros (possivelmente seus futuros senhores), ao chegarem no Brasil acabavam aprimorando esse conhecimento. (PETTER, 2005).

Tal prerrogativa não isentou a entrada de termos africanos na constituição do léxico do português brasileiro. Estudos ainda do século XVII apresentam relatos e pesquisas sobre as línguas africanas faladas no Brasil, dentre eles podem ser citados os trabalhos de Pedro Dias (1697), "[...] Esse trabalho testemunha o emprego corrente naquela época de uma língua africana, o quimbundo, pelos escravos oriundos de Angola." (PETTER, 2002, p. 125) e Antônio Peixoto, que fora recentemente reeditado por Yeda Pessoa de Castro, sob o título A lingua mina-jejê no Brasil, trabalho que traz um vocabulário contendo termos de línguas africanas usadas na região de Minas Gerais, durante o ciclo do ouro. (CASTRO, 2002).

Esses estudos revelam que no Brasil houve um período em que línguas africanas eram usadas como idioma entre os escravizados (principalmente) e que configuravam ao lado do português, tendo falantes e talvez relevância similar àquela representada pela língua geral indígena.

Petter (2002, p. 123) mostra que entre o português falado no Brasil e aquele falado em Portugal existiam algumas diferenças e que já foram percebidas por muitos estudiosos do século XIX, e que tais discrepâncias poderiam ser explicadas pelo contato que o PB teve com as línguas indígenas e africanas.

Nas seções seguintes pretende-se demonstrar algum dos caminhos que levaram a constituição do português brasileiro observando a participação do léxico de origem africana neste contexto. Para tanto serão abordados teóricos como Margarida Petter, Yeda Pessoa de Castro, Emílio Bonvini para melhor elucidar a influência/permanência do léxico africano no PB.

Inicialmente, serão abordados aspectos históricos, baseados nas pesquisas dos autores acima citados; para entender as relações entre Brasil e Angola no tráfico de escravos. Posteriormente, será realizada uma breve análise de termos que aparecem no Vocabulário elaborado por Pessoa de Castro (2001) a fim de demonstrar o uso corrente 
de tais termos e como estão apresentados no dicionário de Silveira Bueno (1984); a fim de ilustrar que os usos desses termos não estão associados à noção de estrangeirismos.

\section{FORMAÇÃO DO PORTUGUÊS BRASILEIRO: O LÉXICO AFRICANO COMO CONTRIBUINTE PARA A LÍNGUA NACIONAL}

A colonização do Brasil teve a Bahia como primeiro ponto territorial explorado, foi dela que todas as demais concentrações se organizaram; tanto que durante muito tempo os navios negreiros aportavam no cais de Salvador para de lá distribuírem os africanos escravizados pelo resto do país, muitos deles oriundos da Angola.

Até meados do século XVII a língua geral estava sendo usada em parte do Brasil, principalmente para mediar as relações entre portugueses e nativos. Há um indicativo que essa língua seria usada em contextos informais, ficando o português nos registros formais.

Contudo, nestes primeiros séculos, a língua portuguesa encontrara em terras brasileiras um forte concorrente, o Tupi, uma língua franca, empregada em grande parte do território brasileiro. Essa lingua geral era indispensável para a comunicação com os indígenas. Por outro lado, não só eles eram muito numerosos mas eram também os que conheciam o país, levando assim vantagem sobre o colonizador português. (BIDERMAN, 2002, p. 65)

O uso dessa Lingua geral denota as relações entre os colonizadores e os nativos, que por serem maioria e detentores dos conhecimentos sobre o território eram necessários aos portugueses, mostrando que apesar da língua portuguesa ser ensinada pelos jesuítas e ser a língua oficial, a língua geral era usada no cotidiano ${ }^{1}$.

A partir daí a importação de escravos africanos para o Brasil cresce de forma vertiginosa, principalmente em Pernambuco e na Bahia, onde, já no final do século XVI, os africanos ocupavam majoritariamente a base da sociedade colonial brasileira; situação que iria se acentuar no século XVII. Assim, enquanto em São Paulo, no Maranhão e no interior do país (ou seja, nas zonas periféricas da Colônia) a língua geral predominava em função da submissão e aculturação das populações indígenas, a língua portuguesa avançava a partir da Bahia e de Pernambuco, os centros mais dinâmicos e mais intimamente ligados à economia mercantilista, na qual se integrava o projeto colonial brasileiro. (LUCCHESI, 2009, p. 45)

Grande parte desse contingente de africanos escravizados aumenta depois da busca pelo ouro; durante a economia açucareira o tráfico de escravos cresceu e, em relação à escravidão dos indígenas, ultrapassou em números de cativos. Mas foi no século XVIII, com a exploração do ouro na região de Minas Gerais que a língua Geral de fato deixou de ser instrumento válido de comunicação entre "senhor e escravo". Uma vez que os africanos (alguns deles) já conheciam o português (os ladinos), houve uma tentativa de recuperar o português que estava perdendo espaço para a língua geral.

\footnotetext{
${ }^{1}$ Situação semelhante ocorre atualmente na Angola, o português é a língua oficial e é aquela ensinada nas escolas, a variedade de prestígio; mas no cotidiano, nas relações informais o que predomina são os dialetos locais.
} 
A grande onda migratória vinda de Portugal com o ciclo do ouro certamente favoreceu a difusão da língua portuguesa no Brasil, aumentando o acesso dos escravos aos modelos da língua-alvo do segmento dominante e penetrando nas regiões do interior de São Paulo, Minas Gerais e Goiás, onde antes predominava a língua geral. Portanto, esses processos sociodemográficos podem explicar bem mais o retrocesso da língua geral no século XVIII, do que a tão propalada reforma pombalina e a expulsão dos jesuítas do Brasil, na década de 1750. (LUCCHESI, 2009. p. 48).

Lucchesi defende a ideia que o português predominou, em relação à língua geral, por uma questão sócio-histórica. Durante o período de exploração do ouro em Minas Gerais, o país recebeu muitos imigrantes portugueses vindos na esperança de enriquecer com a extração do minério, além do aumento de africanos escravizados; há também o movimento migratório, pois muitos colonos migravam para a região de Minas Gerais e/ou vendiam seus escravos para trabalharem nas minas.

Apesar disso o português aprendido em tais condições destoava, e muito, do português falado na metrópole; assim inicia-se a polarização do português brasileiro, havendo de um lado os ricos e portugueses que tinham contato com o português europeu, de outro as variedades que começavam a surgir representativas dos escravizados, dos colonos mais pobres. Essa situação mostra a evidente relação social no uso da língua, podendo, em um mesmo país, haver variedades que denotam que a língua falada no Brasil não é homogênea. (Lucchesi, 2001, 49/50)

Assim, quando se intensifica a escravidão africana há a necessidade de mudar, pois os escravizados não conheciam a língua franca, ao contrário do português, que muitos já haviam aprendido como um crioulo durante a espera no porto, em Angola. Petter (2005) atenta para o fato de que durante o período de espera para que se completasse a carga do negreiro os escravos ficavam aguardando numa espécie de barracão, em Angola um navio ancorado que servia de abrigo para que eles ficassem até que ocorresse o transporte para as novas terras. Durante esse período muitos já falavam alguma das línguas que compunham o grupo banto e com isso pode-se entender que ali se constituísse uma língua veicular para comunicação entre eles:

[...] Essa situação se caracterizava pela concentração forçada e prolongada de locutores de línguas africanas diferentes, embora tipologicamente próximas, que pôde conduzir, no caso de Angola, à adoção do quimbundo (falado em Luanda e ao longo do rio Kwanza até sua foz) como língua veicular. Por outro lado, nesse mesmo período, ocorreu um contato forçado e prolongado com a língua portuguesa; primeiramente com aquela utilizada pelos "pombeiros", recrutadores de cativos no interior das terras; a seguir, ao longo da costa africana, com os "negreiros", brasileiros, que seriam talvez seus futuros senhores. Para muitos escravos originários de Angola, o multilingüismo encontrado no Brasil, resultante do convívio de línguas africanas e português, não será inédito, o que poderá explicar tanto o emprego de uma língua veicular africana quanto o uso do português falado pelos senhores. (PETTER, 2005, p. 201).

Angola foi um importante entreposto no comércio de escravos, com isso muito das línguas faladas lá foram trazidas para cá. E no campo lexical as influências podem 
ser mais facilmente identificadas, embora a maior parte do léxico seja ainda usada por grupos específicos, ainda há, no Brasil, as línguas secretas (Cafundó e Tabatinga) e em comunidades religiosas há, inclusive, a intenção de resgatar termos africanos para compor os rituais de modo a marcar suas origens. (PETTER, 2005)

Quando os africanos chegam ao Brasil e encontram a lingua geral como instrumento utilizado na comunicação entre colonizadores e nativos, podem ter tido contato com essa língua, mas a redução do número de índios e o aumento da população africana propiciou o maior uso do português pelos africanos escravizados. Já no período de exploração da cana de açúcar há referências aos escravizados que conheciam o português (ladinos) e aqueles que não falavam nada da língua do colonizador (os boçais) (LUCCHESI, 2009. p. 46).

Esse contato maior propicia a permanência da língua portuguesa em terras brasílicas com a apropriação por parte dos escravizados, inicialmente como segunda língua, e aprendida por ouvido e sem uma sistematização das regras gramaticais; posteriormente seus filhos a aprendem como língua materna, mas também sem acesso à gramática portuguesa, agregando assim lacunas que se fazem presentes até os dias atuais, dividindo o domínio da língua em dois grandes blocos: primeiro o daqueles que falam a variedade culta, aprendida nas escolas; o segundo, a variedade popular, geralmente marcada pelo uso nas classes mais pobres.

[...] pode-se afirmar que esses empréstimos foram essencialmente obras de falantes do português que, para expressar uma realidade diferente daquela que era, inicialmente, a sua, emprestaram das línguas africanas as palavras que a designavam, conseguindo assim integrar essas mesmas palavras ao português, depois de um tratamento linguístico apropriado. (BONVINI, 2009, p. 120-121).

Hodiernamente pode-se perceber a presença de termos oriundos de línguas africanas no cotidiano dos brasileiros, a exemplo das palavras moleque, macumba, jagunço. Os elementos da cultura afro acabam centrados nos espaços específicos, como nos grupos religiosos, configurando ainda uma espécie de separação com a cultura europeia, branca. Assim, muitos termos usados no cotidiano desses grupos não aparecem na linguagem popular de todo o país, configurando e persistindo num vocabulário de especialidades.

Dessa forma a grande parte do léxico de base africana se concentra em pequenos grupos, e estes utilizam tais termos em contextos específicos, configurando como uma segunda língua presente em rituais religiosos, como língua secretas (nos casos de Cafundó e tabatinga) ou no vocabulário de religiões afro, e seus participantes aprendendo-a ao passo que aprofundam seus estudos na iniciação religiosa.

As línguas negro-africanas, transplantadas para o Brasil há quase quinhentos anos, sobrevivem hoje sob a forma de línguas especiais, ou seja, como modos de falar próprios de uma faixa etária ou de um grupo de pessoas dedicadas a atividades específicas, de acordo com a formulação clássica estabelecida por Van Gennep (1908). Não se apresentam mais como línguas plenas, mas revelam traços de seu longo e intenso cantata com o português. O seu uso - além de estar associado a grupos específicos - está vinculado a duas funções 
principais: ritual: nos cultos religiosos ditos" afro-brasileiros" e demarcação social: como língua "secreta", utilizada em comunidades negras rurais constituídas por descendentes de antigos escravos, como Cafundó e Tabatinga. (PETTER, 2005, p. 194).

Mesmo nestes contextos não se trata realmente do uso de uma língua africana, são línguas secretas ou de especialidades, mas que trazem o léxico africano sem fazer uso da sua gramática, assim nestes casos há a apropriação do léxico, às vezes adequado a uma sintaxe do português brasileiro. A exemplo da língua de Cafundó, Petter (2002) diz que:

A língua do "Cafundó", cupópia ou falange, denominações pelas quais é conhecida, não é uma língua africana, corresponde ao emprego de termos de origem banto (quimbundo ou quicongo, na maioria) na sintaxe do português local, o dialeto rural de Salto de Pirapora, na região de Sorocaba (SP). Seu uso cumpre uma função de língua especial, secreta, que permite a comunicação somente entre os conhecedores da "língua", afastando os estranhos a seus "segredos". Sua vitalidade está ameaçada pelo emprego mais frequente do português pelos mais jovens, que desconhecem os poucos mais de 167 termos "africanos" que a constituem. (PETTER, 2002, p. 126).

O léxico de origem africana muito contribuiu para a formação do português brasileiro, mas as suas origens exatas e o uso tal qual é realizado na África se perdeu com o passar dos séculos. O que pode ser percebido na atualidade é a presença de termos africanos, usados como parte do léxico do português e, em alguns casos de comunidades mais isoladas, seu uso mais frequente e menos corrente nas demais regiões do país.

\section{AFRICANISMOS OU JÁ BRASILEIRISMOS}

Muitas palavras de origem africana usadas atualmente foram incorporadas à língua portuguesa. Os dicionários gerais não fazem menção à origem dessas palavras e as pessoas desconhecem sua etimologia. Algumas dessas palavras adquiriram outros sentidos, mas é necessário realizar estudos linguísticos com foco nessas lexias para se perceba as contribuições africanas para a formação do português brasileiro.

A seguir, propomos uma breve análise de algumas lexias, a partir do trabalho da professora Yeda Pessoa de Castro, em seu livro Falares africanos na Babia: um vocabulário afro-brasileiro como base etimológica das palavras pesquisadas. No quadro abaixo estão selecionadas as palavras e seus respectivos significados e origem encontrados no vocabulário de Pessoa de Castro, 2001.

Quadro 01: Lexias de origem africana

\begin{tabular}{|l|l|}
\hline \multicolumn{1}{|c|}{ VERBETE } & \multicolumn{1}{c|}{ ORIGEM/ SIGNIFICADO } \\
\hline BABA & (banto) 1. (BA) - s.m. partida de futebol jogada na rua ou na praia. \\
\hline BAGUNÇA & $\begin{array}{l}\text { (banto) (BR) - } \text { s.f. desordem, confusão, baderna, remexido, pândega } \\
\text { ruidosa }\end{array}$ \\
\hline CACHAÇA & $\begin{array}{l}\text { (banto) } 1 \text {. (BR) }- \text { s.f. aguardente que se obtém mediante a fermentação } \\
\text { e destilação do mel ou borras do melaço; qualquer bebida alcóolica. }\end{array}$ \\
\hline CACHIMBO & (banto) $1 .\left({ }^{\circ} \mathrm{PO}\right)$-s.m. pipo de fumar. \\
\hline
\end{tabular}




\begin{tabular}{|l|l|}
\hline CAÇULA & (banto) 1. (BR) -s. 2gen. o mais novo dos filhos ou dos irmãos. \\
\hline CALANGO & (banto) (BR) -s.m. lagarto maior que lagartixa \\
\hline CANGA & (banto) (BR) -s.f. tecido usado como saída de praia. \\
\hline CANJICA & $\begin{array}{l}\text { (banto) 1. (BA) - s.f. papa de milho verde ralado a que se junta leite de } \\
\text { coco, açúcar, cravo e canela. }\end{array}$ \\
\hline CATINGA & $\begin{array}{l}\text { (banto) } 1 .(\mathrm{BR}) \text {-s.f. cheiro fétido e desagradável do corpo humano, } \\
\text { de certos animais e de comidas deterioradas. }\end{array}$ \\
\hline FUXICO & $\begin{array}{l}\text { (banto) } 1 .(\mathrm{BR}) \text {-s.m. remendo, alinhavo de agulha e linha. } 2\left({ }^{\circ} \mathrm{BR}\right)-\mathrm{s} . \\
\text { mexerico, intriga, segredo. }\end{array}$ \\
\hline MANGAR & $\begin{array}{l}\text { (banto) }(\mathrm{BR})-\text { v. zombar, troçar, vangloriando-se; caçoar, afetando } \\
\text { seriedade. }\end{array}$ \\
\hline
\end{tabular}

Fonte: Pessoa de Castro (2001).

Todos os verbetes selecionados na tabela acima são dicionarizados, com exceção do verbete $\mathrm{BABA}$, que é de uso corrente na Bahia, embora não apareça nos dicionários gerais. Os termos selecionados fazem parte do léxico do Brasil de tal forma que confundem sua origem, ou não há mais necessidade em saber. Alguns dos verbetes acima selecionados são de uso mais frequente no Nordeste, a exemplo do verbo MANGAR, que é rotineiramente usado em cidades do interior da Bahia.

(1) Hoje tem baba depois do trabalho, não voltarei cedo.

(2) A casa está uma bagunça.

(3) Não repare na bagunça da casa.

(4) João bebeu muita cachaça ontem.

(5) O Zé bebe muita cachaça, vai acabar morrendo.

(6) Minha avó fumou cachimbo por quase toda vida.

(7) Lucas é o caçula da casa.

(8) Encontrei um calango enorme no fundo da escola.

(9) Quando vou à praia gosto de usar a canga para forrar a areia.

(10) A paróquia está vendendo canjica durante os festejos de São João.

(11) Raquel era uma catinga danada, não sei por quanto tempo estava sem tomar banho.

(12) Por acreditar em tanto fuxico desfez o noivado.

(13) Juca mangou de José durante a aula, por isso brigaram.

Nos exemplos acima pode-se perceber que tais palavras aparecem na linguagem popular, mais precisamente na Bahia, sem contudo fazer referência a sua origem, estão incorporadas ao léxico do português brasileiro de tal forma que já são consideradas brasileirismos, não mais africanismos. Em algumas lexias há ainda uma visão preconceituosa por estarem relacionados ao dialeto nordestino, o exemplo (13) bem ilustra o uso do Mangar como deboche, é bem corrente no interior da Bahia, mas no sudeste, por exemplo, não é tão conhecido e quando o é faz-se referência direta ao dialeto "caipira", atestando-o como uma variação geográfica e social. 
O quadro abaixo apresenta como tais verbetes aparecem em dois dicionários de Silveira Bueno (1984):

Quadro 02: Definição do dicionário de Silveira Bueno

\begin{tabular}{|c|c|}
\hline VERBETE & ORIGEM/ SIGNIFICADO \\
\hline $\mathrm{BABA}$ & s.f. Saliva que escorre da boca; mucosidade que segregam certos animais \\
\hline BAGUNÇA & s.f. Desordem; pândega ruidosa \\
\hline CACHAÇA & $\begin{array}{l}\text { s. f. Aguardente; pinga; gosto ou inclinação que se têm por alguma coisa. } \\
\text { Antigamente era sinônimo de porco (cachaço) ou porca (cachaça). } \\
\text { Como carne fosse muito dura, ajuntavam-lhe aguardente para amolecê- } \\
\text { la. O nome da porca (cachaça) passou a significar a mesma aguardente. } \\
\text { O povo criou numerosos sinônimos: branquinha; água-que-passarinho- } \\
\text { não-bebe; abrideira; fogo; santa branca; caninha; mata-bicho, etc }\end{array}$ \\
\hline CACHIMBO & s.m. Pito, pipa, aparelho composto de recipiente e canudo para fumar. \\
\hline CAÇULA & $\begin{array}{l}\text { s. } 2 \text { gên. O mais moço da família; o último nascido; que se opõe ao } \\
\text { primogênito. }\end{array}$ \\
\hline CALANGO & $\begin{array}{l}\text { s. m. Lagarto. Diz-se também calangro. (Folc.)Forma de desafio de viola, } \\
\text { o mesmo que calanco. }\end{array}$ \\
\hline CANGA & $\begin{array}{l}\text { s.f. Jugo de bois; pau que os moços de fretes põem aos ombros para } \\
\text { suspender fardos; instrumento de suplício na China; (fig) opressão; } \\
\text { domínio }\end{array}$ \\
\hline CANJICA & s.f. Milho cozido com leite, açúcar, canela, etc. Mungunzá \\
\hline CATINGA & $\begin{array}{l}\text { s.f. Cheiro forte e desagradável que se exala do corpo humano, } \\
\text { sobretudo nos negros; fartum, bodum. Var. de caatinga, e de maior uso } \\
\text { que esta última forma; mata que foi roçada; vegetação pouco } \\
\text { desenvolvida. }\end{array}$ \\
\hline FUXICO & s.m. Intriga; mexerico; enredo. \\
\hline MANGAR & v. int. Fazer caçoadas; zombar; escarnecer. \\
\hline
\end{tabular}

Fonte: Bueno (1984).

Ao comparar os quadros 1 e 2 , percebe-se que as lexias são conhecidos em todo o país e apropriados por muitos falantes, sem a predefinição de que tratam-se de palavras de origem africana que foram incorporadas ao léxico do português brasileiro. Em um contexto ou outro há o questionamento da origem de determinada palavra, mas apenas a nível de conhecimento, sem contudo o desejo de trilhar os caminhos que tal termo percorreu até ser, de fato, parte da língua portuguesa falada no Brasil.

Alguns verbetes possuem o mesmo significado que Castro (2001) apresenta em seu vocabulário, outras divergem da significação apresentada por Bueno. A lexia 'baba' assume polissemia, pois tanto serve para designar a saliva que escorre da boca; como para denominar a partida de futebol jogada entre amigos, associação comum na Bahia. Outra palavra que também diverge no significado é 'canga', que, na Bahia, está mais associada ao tecido que se leva para a praia. A palavra 'fuxico' também diverge, mas em casos específicos, pois apresenta um significado a mais, na Bahia também é utilizada para denominar um tipo de artesanato que se faz alinhavando o tecido. As demais 
palavras pesquisados não apresentam maiores divergências, mostrando que o uso ainda corrente não afetou a significação que foi atribuído pelo dicionário.

\section{CONSIDERAÇÕES FINAIS}

A formação do português brasileiro contou com contribuições de outras línguas, a principio, e talvez mais veementemente, das línguas indígenas e africanas, mas também, em menor proporção da língua dos imigrantes que vieram para o país.

Há ainda a carência em se investigar de fato a língua falada no Brasil, a análise lexicográfica denota a importância em observar lexias e suas entradas em dicionários, atestando assim sua vitalidade no PB.

A contribuição dos africanos escravizados foi de grande importância para a constituição da língua nacional, muitos agregaram palavras de seu léxico para designar lexias ainda desconhecidos em terras brasílicas, em topônimos, na culinária, religião, cultura, são inúmeras as áreas que podem ter recebido contribuições lexicais.

Ao analisar as lexias e sua etimologia pode-se perceber que a grande maioria permaneceu com seu significado original, porém adaptando sua fonética ao português brasileiro, adequando sua morfossintaxe ao uso local de tal modo que essas lexias já são contabilizados como parte do léxico do PB.

Entretanto a pesquisa não pretende esgotar o assunto, uma vez que trata-se de um tema amplo e que necessita de uma atenção criteriosa a fim de catalogar, registrar a língua que de fato é usada no Brasil. O trabalho lexicográfico tem por finalidade contribuir para um melhor retrato da realidade linguística do país.

\section{REFERÊNCIAS}

BIDERMAN Maria Tereza Camargo. A formação e a consolidação da norma lexical e lexicográfica no português do Brasil. In: NUNES, José Horta; PETTER, Margarida. História do saber lexical e constituição de um léxico brasileiro. São Paulo: Pontes, 2002, 65-82 p. BONVINI, Emílio. Os vocábulos de origem africana na constituição do português falado no Brasil. In: FIORIN, José Luiz; PETTER, Margarida. África no Brasil: a formação da língua portuguesa. 2. ed. São Paulo: Contexto, 2009. 101-144 p.

BUENO, Francisco da Silveira. Dicionário escolar da Lingua Portuguesa. 11. ed. Rio de Janeiro: FAE, 1984.

CASTRO, Yeda Pessoa de. Falares africanos na Babia:um vocabulário afro-brasileiro. 2. ed. Rio de Janeiro: Topbooks, 2001. . A lingua mina-jeje no Brasil. Belo Horizonte: Fundação João Pinheiro, 2002. 
LUCCHESI, Dante. História do contato entre línguas no Brasil. In: LUCCHESI, Dante; BAXTER, Alan; RIBIRO, Ilza. (org.) O português afro-brasileiro. Salvador: EDUFBA, 2009. $41-73$ p.

PETTER, Margarida. Termos de origem africana no léxico do português do Brasil. In: NUNES, José Horta; PETTTER, Margarida. História do saber lexical e constituição de um léxico brasileiro. São Paulo: Pontes, 2002. $123-145$ p.

Línguas africanas no Brasil. Disponível em: <http://www.gragoata.uff.br/index.php/gragoata/article/view/351/350>. Acesso em: 17 ago. 2017.

Recebido em: 05/06/2018 Aprovado em: 23/07/2018 Publicado em: 31/12/2018 